\title{
A PHOTON BEAM POSITION MONITOR FOR SSRL BEAMLINE 9
}

\author{
John A. Cerino, Thomas Rabedeau, William Bowen \\ Stanford Linear Accelerator Center, Stanford Synchrotron Radiation Laboratory, \\ Stanford California 94309, USA
}

\begin{abstract}
We present here the concept of a simple one dimensional photon beam position monitor for use with high power synchrotron radiation beams. It has micron resolution, reasonable linearity in an inexpensive design. Most important, is its insensitivity to diffusely scattered low energy radiation from components upstream of the monitor.
\end{abstract}

Presented at the International Conference on Synchrotron Radiation Instrumentation (SRI '94), Stony Brook, New York, July 18-24, 1994

\section{DISCLAIMER}

\begin{abstract}
This report was prepared as an account of work sponsored by an agency of the United States Government. Neither the United States Government nor any agency thereof, nor any of their employees, makes any warranty, express or implied, or assumes any legal liability or responsibility for the accuracy, completeness, or usefulness of any information, apparatus, product, or process disclosed, or represents that its use would not infringe privately owned rights. Reference herein to any specific commercial product, process, or service by trade name, trademark, manufacturer, or otherwise does not necessarily constitute or imply its endorsement, recommendation, or favoring by the United States Government or any agency thereof. The views and opinions of authors expressed herein do not necessarily state or reflect those of the United States Government or any agency thereof.
\end{abstract}

Work supported by the U.S. Department of Energy under Contract DE-AC03-76SF00515
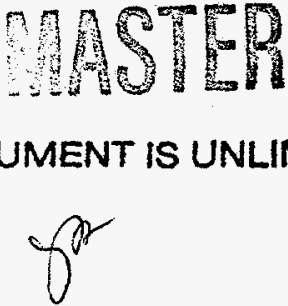


\section{INTRODUCTION}

SSRL is currently constructing Beamline 9, a hard $x$-ray beamline for use in structural molecular biology research. It is generated in the SPEAR $3 \mathrm{GeV}$ electron storage ring by an 8 period hybrid wiggler magnet with a peak field of 1.9 Tesla, a period length of $26 \mathrm{~cm}$, and a field integral over $1 / 2$ period of $\sim 17 T-\mathrm{cm}$. It produces a $16 \mathrm{mrad}$ fan of radiation which is split into three branch lines as depicted in Figure 1. The critical energy of the radiation is $11400 \mathrm{eV}$.

Beam position control is a major consideration in the quality of research results obtained on this and other synchrotron radiation beamlines. To achieve the best control of the beam position at the experiment with a single position monitor, the monitor should be located at a similar distance from the source. In such downstream locations, monitors previously used at SSRL, (ion chambers and photo-electron devices) often suffer intensity dependent drift as the result of bend magnet radiation contamination, aperture vignetting, or spray from upstream components such as mirrors and beam stoppers.

In order to avoid these problems we have devised a position monitor which utilizes fluorescence radiation from a cooled copper target placed directly in the wiggler beam. This monitor will be placed in the gap between 2 branch lines near the horizontal centerline of the wiggler radiation fan.

A similar device was reported by Stefan et al ${ }^{1}$ in 1986, but it was detector limited and somewhat complex in design.

\section{PRINCIPLE OF OPERATION}

For centuries, astronomers have measured the position of celestial objects using the occultation of light sources. ${ }^{2}$ We employ that technique here to monitor beam position.

A water-cooled copper target is placed in the direct wiggler beam. The target surface which faces the incoming radiation is planar and is sloped at $\sim 10^{\circ}-15^{\circ}$ to the median plane of the incident beam in order to reduce the absorbed power density and resultant heating.

Incident $\mathrm{x}$-rays having energy above the $\mathrm{Cu} k$ edge at $8979 \mathrm{eV}$ will excite fluorescence in the target which is viewed by a pair of silicon PIN photodiodes. ${ }^{3}$ The field of view of each diode is occluded such that one diode views only the portion of the target above the median plane and the other views the portion below. Vertical motion of the beam increases the flux into one diode while reducing the flux into the other. The difference signal can be fed back to the electron beam steering system to maintain the beam position.

Scattered radiation spray from upstream objects such as mirrors and slits is predominantly low energy, and hence will not excite fluorescence in the $\mathrm{Cu}$ target. Thus, in contrast to photo-electron or ion chamber based monitors, the fluorescence beam position monitor should be less sensitive to this spray. 
Because the device uses secondary hard $x$-rays, only the stationary $\mathrm{Cu}$ target need be inside the beam transport vacuum system. The detector diodes, slits, occulting mask, and any adjustments can be outside of the vacuum, viewing the target through a beryllium window. Figure 2 shows a schematic diagram of the position monitor.

\section{TEST RESULTS}

A prototype position monitor was tested in Beamline 2-2 at SSRL, a bending magnet beamline with a critical energy of $4700 \mathrm{eV}$; hence a useful flux for producing $\mathrm{Cu}$ fluorescent $x$-rays approximately $10^{-2}$ that of Beamline 9 for a given horizontal acceptance.

A fixture which carries a copper plate tilted at $-10^{\circ}$ to the beam median plane, the diodes, and the slits was mounted on a vertical sample positioner in the experimental hutch of the white radiation branch of Beamline 2.

The beam was defined by a horizontal slit to be $-5 \mathrm{~mm}$ wide; corresponding to -0.25 mrad of beam. In the vertical it was limited only by the built-in apertures of the beamline. In order to not disturb other users of the beamline, the beam was left in its steered position and the position monitor was scanned vertically for the tests. The diode signals were fed through Keithley current amplifiers.

The photodiodes delivered $\sim 10^{-7} \mathrm{~A}$ at $100 \mathrm{~mA}$ stored current in SPEAR. Figure 3 is a plot of the normalized difference signal of the position monitor.

Figure 4 shows the response of the position monitor to motion in steps of 2.5 microns. The noise on the signal is actual motion of the photon beam relative to the monitor prototype.

\section{ELECTRONIC CIRCUITRY}

In order to take advantage of the relatively high output of the AXUV photodiodes (100$1000 \mathrm{nA}$ ) available in our application, we are designing a low cost dual channel preamplifier to replace a pair of Keithley current amplifiers.

Because we are using the photodiode pair to generate an error signal, we are more concerned with inter-channel matching and stability than absolute linearity. Hence we plan to use a dual channel op-amp selected for its precision and small voltage offset rather than superior input bias current specification.

Since the signal to noise ratio is best when the gain is at its highest, we require a variable gain amplifier.

The preamp is located a few inches from the diodes to minimize noise pickup so it is not readily accessible for adjustment. In order to avoid sending the gain loop to a switch over a long cable, we plan to use a dual channel analog multiplexer to select the appropriate gain resistors remotely. In this way we can send a relatively noise immune 2-bit control signal to the multiplexer to switch among four different gain settings. 
Finally, a balance control will permit small adjustments of the relative gain between channels.

\section{ACKNOWLEDGEMENTS}

SSRL is funded by the U.S. Department of Energy, Office of Basic Energy Sciences. Support for Beamline 9 is provided by the DOE Office of Health and Environmental Research.

\section{REFERENCES}

1. P. M. Stefan., D.P. Siddons, and J.B. Hastings, "A New Beam Position Monitor for X-ray Synchrotron Facilities", Nucl. Instrum. Methods A 255, 598 (1987).

2 e.g., Newgrange, Ireland and Stonehenge, England.

3 AXUV-100 made by INTERNATIONAL RADIATION DETECTORS Torrance, CA. 


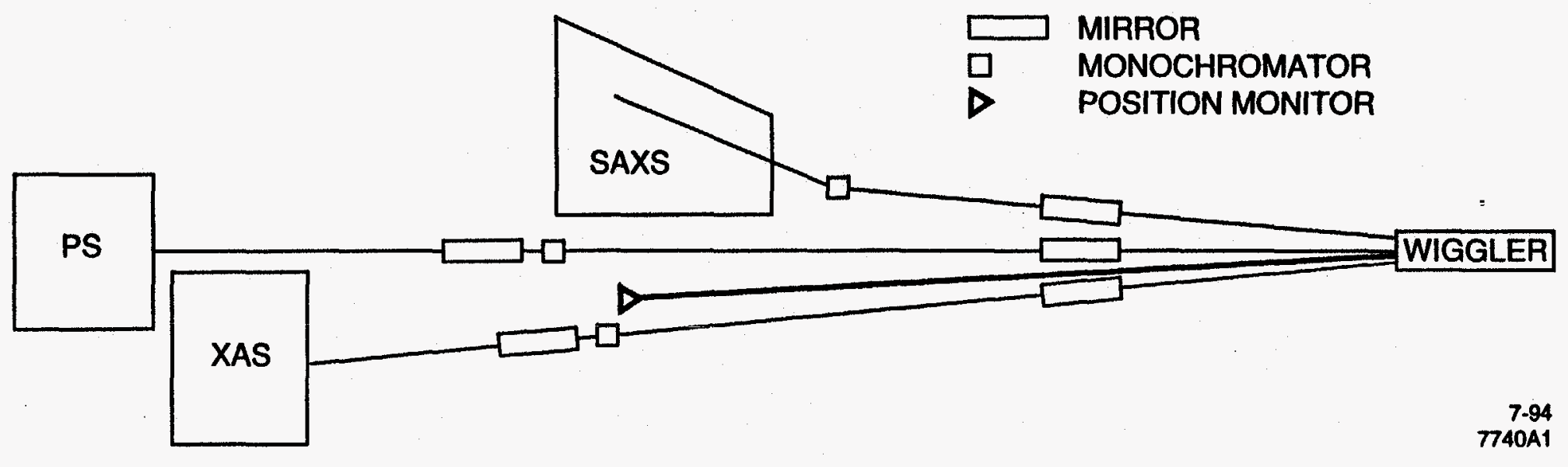

Fig. 1 Beamline 9 Schematic 


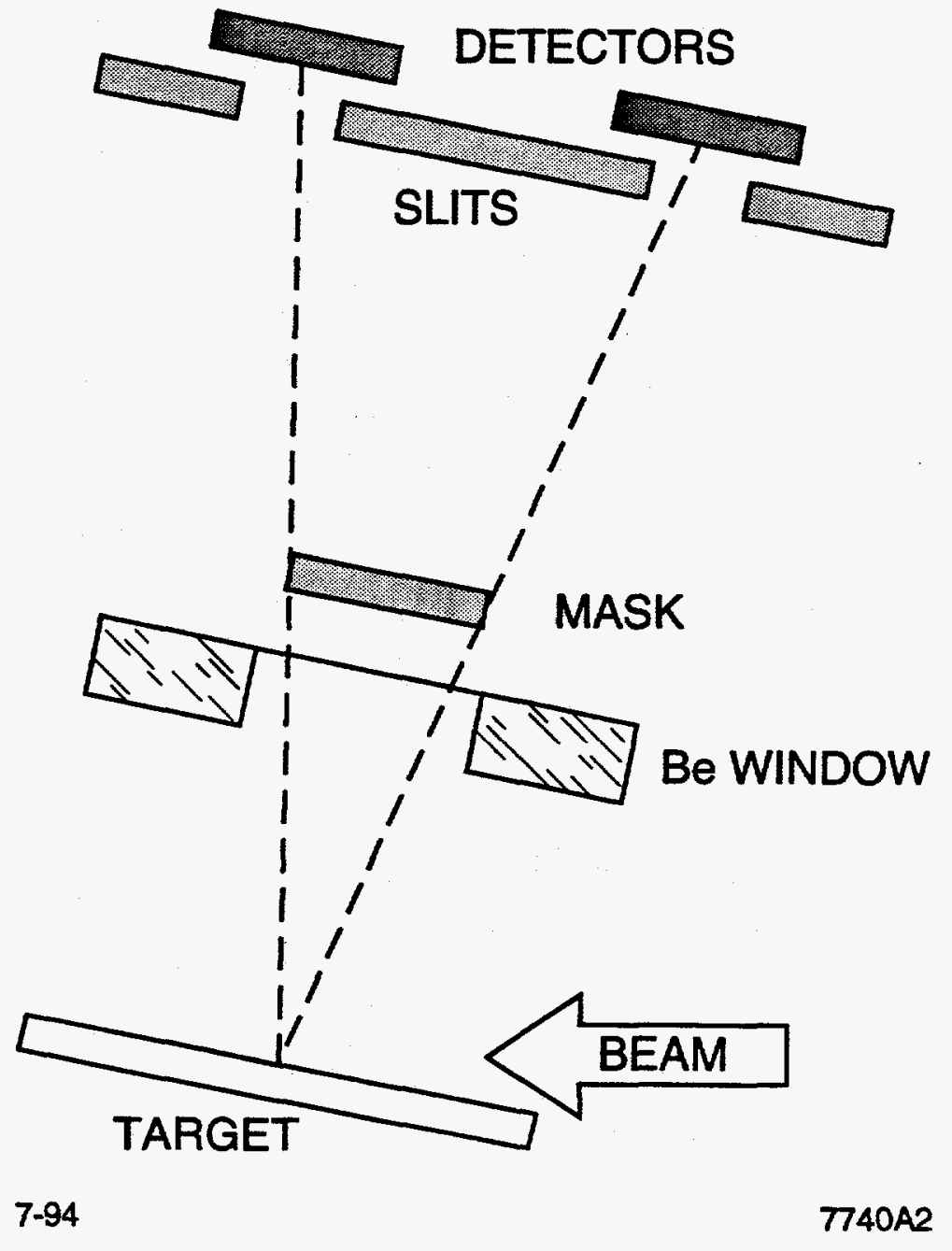

Fig. 2 Position Monitor Schematic 


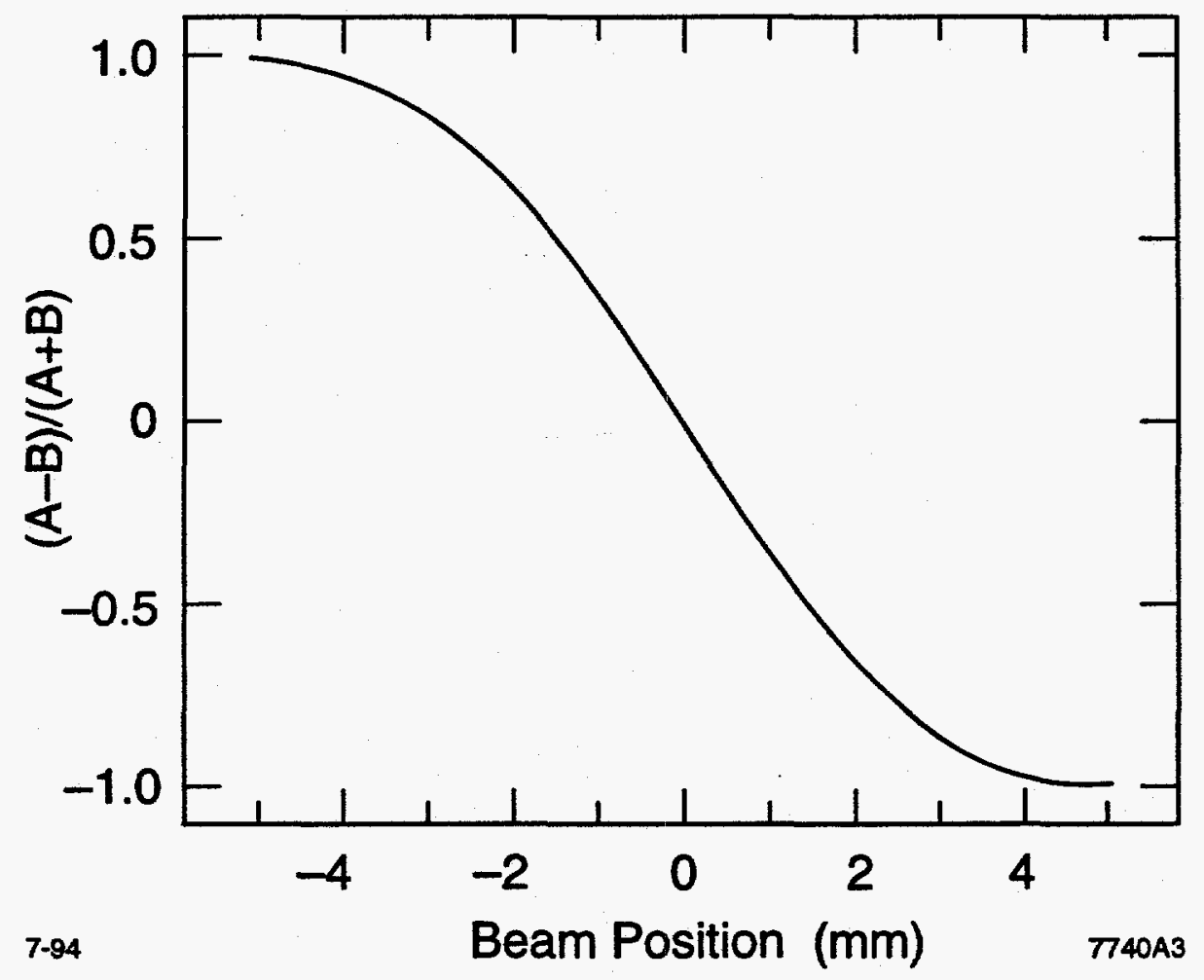

Fig. 3 Normalized Position Monitor Signal 


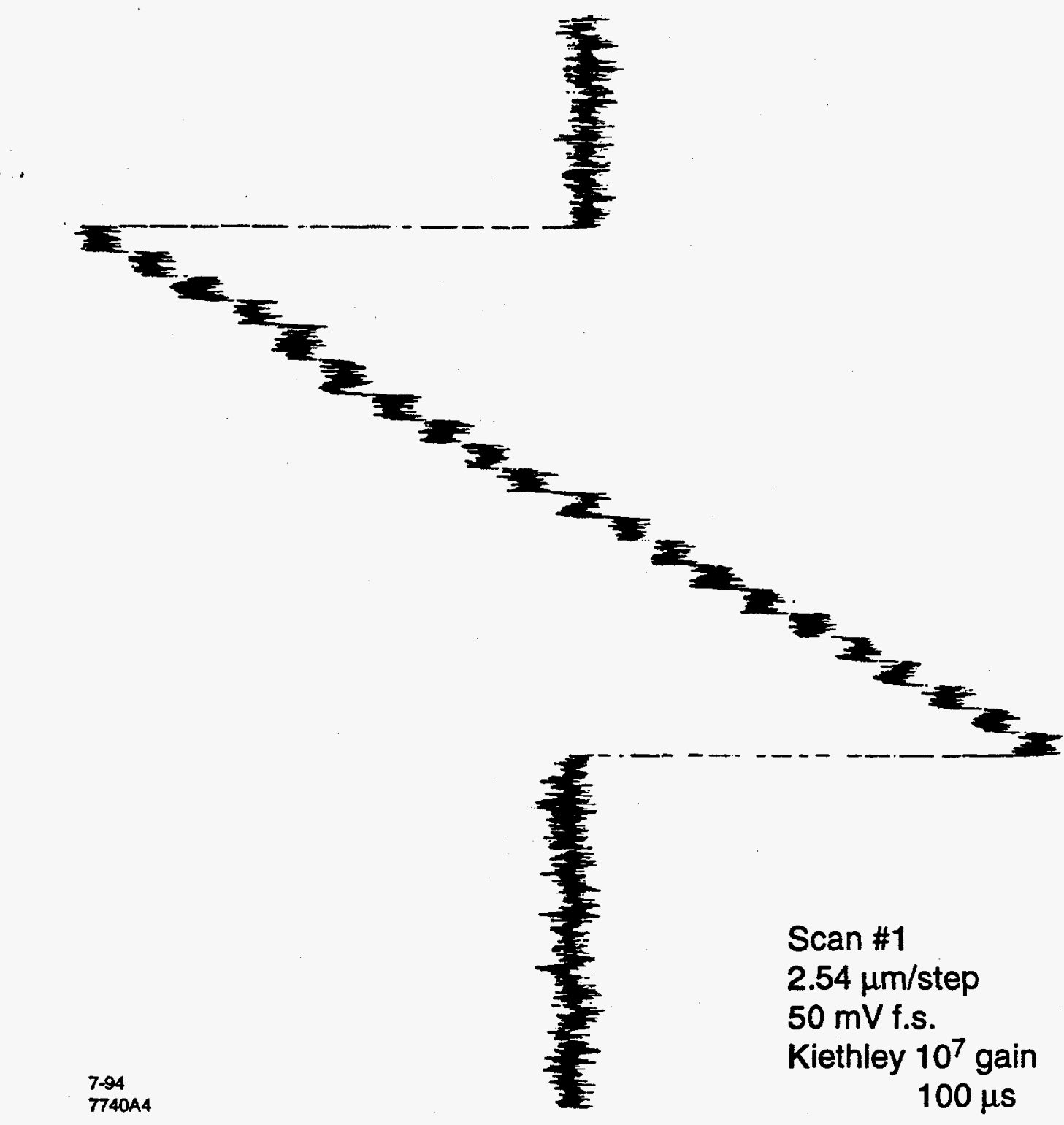

Fig. 4 Scan in 2.5 micron steps 


\section{DISCLAMIER}

Portions of this document may be illegible in electronic image products. Images are produced from the best available original document. 